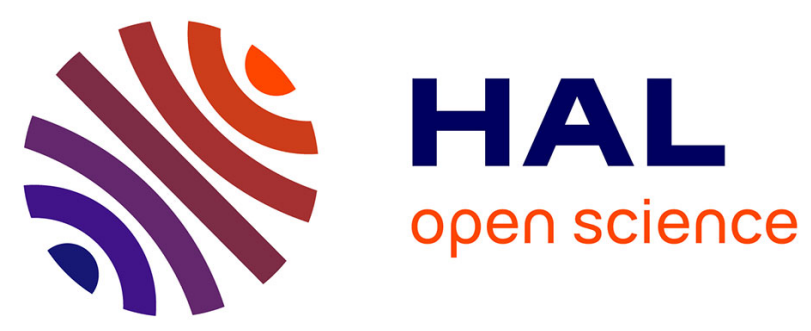

\title{
The Impact of Digital Technologies on Services Characteristics: Towards Digital Servitization
}

David Romero, Paolo Gaiardelli, Giuditta Pezzotta, Sergio Cavalieri

\section{To cite this version:}

David Romero, Paolo Gaiardelli, Giuditta Pezzotta, Sergio Cavalieri. The Impact of Digital Technologies on Services Characteristics: Towards Digital Servitization. IFIP International Conference on Advances in Production Management Systems (APMS), Sep 2019, Austin, TX, United States. pp.493-501, 10.1007/978-3-030-30000-5_61. hal-02419200

\section{HAL Id: hal-02419200 \\ https://hal.inria.fr/hal-02419200}

Submitted on 19 Dec 2019

HAL is a multi-disciplinary open access archive for the deposit and dissemination of scientific research documents, whether they are published or not. The documents may come from teaching and research institutions in France or abroad, or from public or private research centers.
L'archive ouverte pluridisciplinaire HAL, est destinée au dépôt et à la diffusion de documents scientifiques de niveau recherche, publiés ou non, émanant des établissements d'enseignement et de recherche français ou étrangers, des laboratoires publics ou privés. 


\title{
The Impact of Digital Technologies on Services Characteristics: Towards Digital Servitization
}

\author{
David Romero ${ }^{1}$, Paolo Gaiardelli², Giuditta Pezzotta ${ }^{2}$, Sergio Cavalieri ${ }^{2}$ \\ ${ }^{1}$ Tecnológico de Monterrey, Mexico \\ david.romero.diaz@gmail.com \\ ${ }^{2}$ University of Bergamo, Italy \\ paolo.gaiardelli@unibg.it; giuditta.pezzotta@unibg.it; \\ sergio.cavalierieunibg.it
}

\begin{abstract}
Despite that digital technologies play a fundamental role in enabling innovation in service delivery processes, the understanding of how they influence services characteristics, and service provider - customer interactions still remains a critical point. On these premises, this paper introduces a study to explore such influences, through the adoption of a two-dimensional matrix, representing a service provider - customer interaction typology, and describing how digital technologies influence the five main services characteristics (viz. intangibility, inventory, inseparability, inconsistency, and involvement). The matrix was built upon a literature review, and further refined through brainstorming sessions with researchers and practitioners. The results found suggest that digital servitization, the "digital transformation of services", brings about new dynamics in service provider - customer interactions by impacting on the service delivery processes elements. For this reason, the achieved matrix can help service researchers and managers to understand how digital technologies increase/decrease the presence and the role of the service provider in a service delivery process, and the presence and the role of the customer of the service in a service delivery itself.
\end{abstract}

Keywords: Service Systems, Product-Service Systems, Digitalization, Digital Technologies, Services Characteristics, Service Provider, Customer, Interactions.

\section{Introduction}

Recent studies have addressed the role of digital technologies in services and productservice bundles delivery processes towards digital servitization [1] [2]. As suggested by [3] \& [4], the digitalization of services influences the nature of a service itself, including its characteristics, since it implies a "(re-)organisation" of the service delivery process. Despite the large interest of research towards digital technologies in the service industry, often too little attention is still given to exploring how services characteristics [5] are evolving when digital technologies [6] are introduced in service delivery processes, thus, creating new forms of service provider-customer interactions. Such knowledge would instead allow to better develop and organise processes and resources, as well as to identify the most suitable digital technologies (e.g. see Table 1) to be adopted for a specific service or product-service delivery solution. In such a context, this paper aims to analyse how digital technologies influence the characteristics of services in existing and new service provider - customer interactions as they are digitalized in B2C \& B2B domains. To do this, we classify digital technologies in a two-dimensional matrix, and use this categorisation to verify how they affect each of the "characteristics of services". 
Table 1. Digital Technologies and their Impact on Services: Examples

\begin{tabular}{|c|c|}
\hline $\begin{array}{l}\text { Augmented Reality (AR) / } \\
\text { Virtual Reality (VR) }\end{array}$ & $\begin{array}{l}\text { - } \mathrm{AR} \text { / VR can improve customer support agents training. } \\
\text { - } \mathrm{AR} \text { / VR can enrich services "tangibility", thus, customer experience. }\end{array}$ \\
\hline $\begin{array}{l}\text { Autonomous Guided } \\
\text { Vehicles (AGVs) }\end{array}$ & - AGVs can support service delivery processes (e.g. logistics services). \\
\hline Chatbots & - Chatbots can improve the availability of customer service and support. \\
\hline $\begin{array}{l}\text { Big Data Analytics } \\
\text { (BDA) }\end{array}$ & $\begin{array}{l}\text { - BDA insights integration with human, assisted, or automated service } \\
\text { delivery processes can ultimately improve customer experience. }\end{array}$ \\
\hline $\begin{array}{l}\text { Cloud Computing } \\
\text { (CC) }\end{array}$ & $\begin{array}{l}\text { - } \mathrm{CC} \text { resources "elasticity" can offer at each point in time the needed } \\
\text { resources to match the current service demand as closely as possible. }\end{array}$ \\
\hline $\begin{array}{l}\text { Horizontal Integration (HI) / } \\
\text { Vertical Integration (VI) }\end{array}$ & $\begin{array}{l}\text { - HI / VI can improve service delivery processes, and services quality, } \\
\text { by enriching the value creation capabilities of a service value chain. }\end{array}$ \\
\hline $\begin{array}{l}\text { Internet of Things } \\
\text { (IoT) }\end{array}$ & $\begin{array}{l}\text { - IoT can improve the delivery of current, and provisioning of new } \\
\text { services to smart, connected products } \& \text { assets (e.g. product-services). }\end{array}$ \\
\hline Simulations & - Advanced simulations will continue to support the design of services. \\
\hline
\end{tabular}

\section{Services: Categories, Characteristics, and Types of Interaction}

Among different perspectives and interpretations of service features, the majority of studies in the service domain attribute five distinctive characteristics to services, also known as the five "I's" [5]. These are: (i) Intangibility, since services are intangible; (ii) Inventory (perishability), since services cannot be stored; (iii) Inseparability, since service provider is indispensable for a service delivery; (iv) Inconsistency (variability), since each service is unique; and (v) Involvement, since services require customer participation in the service delivery process.

Based on these characteristics, different classification methods both in marketing and in services operations management areas have been developed over the years to describe the main service dimensions and their relationships [7]. An exploration in the field of service process delivery has been carried out to develop a better understanding of how service provider - customer interactions co-create value in the emerging digital servitization domain [8]. In this context, [9] have proposed a service classification, where the level of participation of the customer in the service delivery process goes from (i) self-services, defined as "services in which there is no direct assistance from or interaction with a human service provider" to (ii) super-services, defined as "services in which there is no direct participation of the human customer". On the other hand, [10] has proposed a classification where the level of participation of humans goes from (i) human-services, defined as "services in which there is direct assistance from or interaction between the human service provider and the human customer" to (ii) autonomous-services, defined as "services in which there is no interaction between the human service provider and the human customer".

Hence, based on the categorisations of [9] \& [10], we can argue that in a digitalized service delivery process, four types (i-iv) of service provider - customer interactions can exist. These interactions depend on: (a) the presence (i.e. yes/no) and the role (i.e. active/passive) of the service provider in a service delivery process, and (b) the presence (i.e. yes/no) and the role (i.e. active/passive) of the customer of the service in a service delivery itself. Table 2 describes the four types of interactions that have been identified in this research: (i) Human to Human $(\mathrm{H} 2 \mathrm{H})$, where digital technologies do not modify 
the "active role" of the human service provider, neither the human customer, in the human-service delivery process. However, they can create new forms of or enrich their interactions (e.g. augmented reality, virtual reality, mixed reality, and haptic devices), or allow these interactions to take place remotely and in real-time (e.g. phone-calls, instant messaging, and video conferencing); (ii) Human to Machine (H2M), where digital technologies enable the possibility of a human self-service process, thanks to an intuitive human-machine interface already available in the machine service provider. Within this type, the human customer is the only "active part" in the service delivery process; (iii) Human to Machine (H2M), where digital technologies allow the possibility of a super-service process, thanks to remote operation capabilities. These capabilities allow the human service provider to act on behalf of the customer, and make the human customer a "passive entity" in the service delivery process; and (iv) Machine to Machine $(M 2 M)$, where digital technologies create an autonomous-service delivery process, thus, making unnecessary the existence of a human-machine interface in order to deliver the service. Therefore, both human service provider, and human customer presences are "passive" or "inexistent" in the service delivery process.

Table 2. Service Provider - Customer Interaction Typology

\begin{tabular}{|c|c|c|}
\hline & Passive & Active \\
\hline Passive & $\begin{array}{c}\text { Machine to Machine - M2M } \\
\text { (autonomous-service) }\end{array}$ & $\begin{array}{c}\text { Human to Machine - H2M } \\
\text { (super-service) }\end{array}$ \\
\hline Active & $\begin{array}{c}\text { Human to Machine - H2M } \\
\text { (self-service) }\end{array}$ & $\begin{array}{c}\text { Human to Human - H2H } \\
\text { (human-service) }\end{array}$ \\
\hline
\end{tabular}

\section{The Evolution of Services Characteristics}

This section discusses how digital technologies influence the characteristics of services (viz. intangibility, inventory (perishability), inseparability, inconsistency (variability), and involvement [5]) as a result of their digitalization in the above-mentioned service provider - customer interaction typology (see Tables 3 to 7 ).

\subsection{Intangibility}

Based on the service provider - customer interaction nature, determined by the role of digital technologies in the "service delivery process", the degree of intangibility of a service can be classified as: "low, medium, or high", depending on two main factors: (a) the presence of the human customer of the service in a service delivery process, and (b) the contribution of the digital technologies to give a sense of <tangibility> to the service itself. Hence, in the first interaction-type, human service provider to human customer (i.e. human-service), the service degree of intangibility is considered: "low", because of a face-to-face and/or a virtual interaction takes place in real-time between the two parties involved, making the service delivery process more vivid, and therefore, more tangible. In the second and third interaction-types, the degree of intangibility is considered: "medium", since in both types, being human customer to machine service provider (i.e. self-service), or human service provider to machine customer (i.e. superservice), a human-machine interface will permit a certain live-experience of the service delivery process for the human as a customer, or as a service provider, and a user 
interface will allow a certain tangibility of the service itself. Lastly, in the fourth interaction-type, the service degree of intangibility is considered: "high", due to an autonomous-service delivery process (i.e. autonomous-service) in a machine service provider to machine customer interaction, making the service delivery process completely intangible for the human as a customer, or as a service provider.

Table 3. Intangibility in Service Provider - Customer Interaction-Types

\begin{tabular}{|c|c|c|}
\hline & Passive & Active \\
\hline Passive & $\begin{array}{c}\text { M2M } \\
\text { (high intangibility in autonomous-services) }\end{array}$ & $\begin{array}{c}\mathrm{H} 2 \mathrm{M} \\
\text { (medium intangibility in super-services) }\end{array}$ \\
\hline Active & $\begin{array}{c}\mathrm{H} 2 \mathrm{M} \\
\text { (medium intangibility in self-services) }\end{array}$ & (low intangibility in human-services) \\
\hline
\end{tabular}

\subsection{Inventory (perishability)}

Based on a service physical or digital nature, its capability for being stored may change, and can be classified as: "low, medium, or high". In this sense, a physical service cannot be stored, but a digital service can be in what computer scientists call a services library or a services directory. Digital services can be retrieved from digital storage, manually or automatically, for their (i) execution as they are, (ii) customization/configuration first and later execution, or (iii) composition with other digital services for the co-creation of a particular meta-service, or service bundles. Thus, in the first interaction-type, human service provider to human customer (i.e. human-service), a physical service cannot be stored due to its physical nature, and human delivery channel. Therefore, digital technologies can only facilitate the service delivery process, and as a result, its perishability level is considered: "high". In the second interaction-type, human customer to machine service provider (i.e. self-service), a digital (standard) service can be stored in a service delivery device, and the human customer can consume it on-demand. So, digital technologies act as a service delivery channel, and the service perishability level is considered: "low" since we are referring to the consumption of a digital (standard) service. In the third interaction-type, human service provider to machine customer (i.e. super-service), a physical service or a digital (standard) service cannot be stored and/or consumed on-demand. Consequently, digital technologies can only help to make more efficient the delivery processes, since some level of customization/configuration may be needed before for the service delivery, and as a result, the perishability level is considered: "medium". Lastly, in the fourth interaction-type, machine service provider to machine customer, digital (standard) services can be stored in an e-library or edirectory, so that digital technologies can create autonomous-services without human intervention as a customer or as a service provider, and as a result their perishability level is considered: "low".

Table 4. Inventory (perishability) in Service Provider - Customer Interaction-Types

\begin{tabular}{|c|c|c|}
\hline & Passive & Active \\
\hline Passive & $\begin{array}{c}\mathrm{M} 2 \mathrm{M} \\
\text { (low perishability in autonomous-services) }\end{array}$ & $\begin{array}{c}\mathrm{H} 2 \mathrm{M} \\
\text { (medium perishability in super-services) }\end{array}$ \\
\hline \multirow{2}{*}{ Active } & $\begin{array}{c}\mathrm{H} 2 \mathrm{M} \\
\text { (low perishability in self-services) }\end{array}$ & $\begin{array}{c}\mathrm{H} 2 \mathrm{H} \\
\text { (high perishability in human-services) }\end{array}$ \\
\hline
\end{tabular}




\subsection{Inseparability}

Based also on the service provider - customer interaction nature, determined by the role of digital technologies, and their "automation capabilities", the degree of inseparability between the human service provider and the service delivery process can be classified as: "low, medium, or high". Hence, in the first interaction-type, human service provider to human customer, the degree of inseparability is considered: "high", since we are dealing with a human-service. In the second and third interaction-types, the degree of inseparability is considered: "medium", since in both cases, it would be possible to automate the human service provider role or the human customer role correspondingly, being the cases for self-services and super-services. Lastly, in the fourth interactiontype, the degree of inseparability is considered: "low", because we are referring to an autonomous-service delivery process that does not require human intervention in the role of a service provider or a customer.

Table 5. Inseparability in Service Provider - Customer Interaction-Types

\begin{tabular}{|c|c|c|}
\hline & Passive & Active \\
\hline Passive & $\begin{array}{c}\mathrm{M} 2 \mathrm{M} \\
\text { (low inseparability in autonomous-services) }\end{array}$ & $\begin{array}{c}\mathrm{H} 2 \mathrm{M} \\
\text { (medium inseparability in super-services) }\end{array}$ \\
\hline Active & $\begin{array}{c}\mathrm{H} 2 \mathrm{M} \\
\text { (medium inseparability in self-services) }\end{array}$ & $\begin{array}{c}\mathrm{H} 2 \mathrm{H} \\
\text { (high inseparability in human-services) }\end{array}$ \\
\hline
\end{tabular}

\subsection{Inconsistency (variability)}

Based on a service physical or digital nature, its replicability and quality standardization in a service delivery process can be more or less easy to manage, so considering the complexity of its exact reproducibility, its variability level can be classified as: "low, medium, or high". Thus, in the first interaction-type, human service provider to human customer, the service has a physical and a human-service nature. Therefore, allowing high possibilities of service inconsistencies, since both service provider and customer are humans, and they could find difficult to reproduce exactly a previous service and its delivery experience, consequently, the service variability level is considered: "high". In the second interaction-type, human customer to machine service provider, service inconsistencies, in the context of self-services, have a tendency to be medium. Indeed, the human customer role is partially standardized by means of a <wizard> in the selfservice user interface, and the machine service provider process is fully standardized in order to manage customer expectations. Consequently, the service variability level is considered: "medium-low". In the third interaction-type, human service provider to machine customer, service inconsistencies, in the context of super-services, also have a tendency to be medium, since the machine service provider aims for developing a catalogue of standard services or a service configurator in order to facilitate itself the delivery of different services as they are needed by the human customer. Thus, the service variability level is considered: "medium-high". Lastly, in the fourth interactiontype, machine service provider to machine customer, services inconsistencies tend to be very low, as the automation of a service delivery process requires the standardization of the service itself. Hence, service variability level is considered: "low". 
Table 6. Inconsistency (variability) in Service Provider - Customer Interaction-Types

\begin{tabular}{|c|c|c|}
\hline & Passive & Active \\
\hline Passive & $\begin{array}{c}\mathrm{M} 2 \mathrm{M} \\
\text { (low variability in autonomous-services) }\end{array}$ & $\begin{array}{c}\mathrm{H} 2 \mathrm{M} \\
\text { (medium-high variability in super-services) }\end{array}$ \\
\hline \multirow{2}{*}{ Active } & $\begin{array}{c}\mathrm{H} 2 \mathrm{M} \\
\text { (medium-low variability in self-services) }\end{array}$ & $\begin{array}{c}\mathrm{H} 2 \mathrm{H} \\
\text { (high variability in human-services) }\end{array}$ \\
\hline
\end{tabular}

\subsection{Involvement}

Based also on the service provider - customer interaction nature, human involvement in the service creation and service delivery process can be classified as: "low, medium, or high". In the first interaction-type, human service provider to human customer, the human nature of the service makes essential the human involvement of both parties, hence, human involvement is considered: "high". In the second interaction-type, human customer to machine service provider, due to the self-service approach in the service delivery, only the human customer is needed, thus, human involvement is considered: "medium". In the third interaction-type, human service provider to machine customer, because of the super-service approach in the service delivery, only the human service provider is needed, therefore, human involvement is considered: "medium". Lastly, in the fourth interaction-type, machine service provider to machine customer, autonomousservices make human involvement unnecessary, and therefore, human involvement is considered: "low" or "null".

Table 7. Involvement in Service Provider - Customer Interaction-Types

\begin{tabular}{|c|c|c|}
\hline & Passive & Active \\
\hline Passive & $\begin{array}{c}\text { M2M } \\
\text { (low involvement in autonomous-service) }\end{array}$ & $\begin{array}{c}\mathrm{H} 2 \mathrm{M} \\
\text { (medium involvement in super-services) }\end{array}$ \\
\hline Active & $\begin{array}{c}\mathrm{H} 2 \mathrm{M} \\
\text { (medium involvement in self-services) }\end{array}$ & $\begin{array}{c}\mathrm{H} 2 \mathrm{H} \\
\text { (high involvement in human-services) }\end{array}$ \\
\hline
\end{tabular}

\section{Discussion}

The level of usage of digital technologies in a service delivery process influences the characteristics of services. Such influence is in some cases is "positive" and, in others, "negative". For instance, as the level of usage of digital technologies increases in a service delivery process, the degree of service intangibility increases (see Sub-section 3.1), since the physical interaction between the human customer and the human service provider gets reduced. On the contrary, when it comes to the service inseparability (see Sub-section 3.3), the level of usage of digital technologies in a service delivery process decreases this characteristic, since technology makes possible to separate the customer from the service provider by using technology as an interface between them.

Furthermore, the influence exerted by the digital technologies in a service delivery process, and as a consequence on the characteristics of a service, is mediated by the type of interaction that is established between the customer and the service provider. For example, although service inconsistency (see Sub-section 3.4) decreases as digital technologies are used in a service delivery process, due to the process standardization, 
it decreases more quickly in the case of self-service solutions because the process is directly controllable by the service provider to ensure its effectiveness.

Again, the influence of services characteristics resulting from the different levels of usage of digital technologies in the four types of service provider - customer interactions in turn impacts on the organisation and management of a service delivery process. Such impacts are briefly reported as follow: (i) When it comes to service intangibility, digital technologies increase this characteristic, and involve shifting the service physical evidence from humans (e.g. the technician uniform) to technology (e.g. computer interfaces); (ii) When it comes to services inventory (perishability), digital technologies can reduce the problems that traditionally affect the variability of services demand, including their design and availability management, as digital technologies can create "virtual buffers", and offer "elasticity" of digital resources (e.g. cloud ICTinfrastructures). However, particular attention must be paid to balancing the capability and capacity of a service delivery process; (iii) When it comes to the inseparability of the service provider - customer, the attention of the service provider shifts from being focused on the front-office activities (i.e. H2H) to the back-office activities (i.e. H2M), up to concentrating only on support activities when both customer and service provider are excluded from the service delivery process in a machine service provider to machine customer context (i.e. M2M); (iv) When it comes to services inconsistency (variability), its reduction in a service deliver process involves an increased "standardization" of overall service system (i.e. processes, competencies, and resource involved); and (v) When it comes to the human service provider and/or human customer involvement, the reduction of participation of humans in a service delivery process reduces the necessary efforts to make tangible "the intangible", because human customers are not interested in participating in the service delivery process, but they could still be interested in participating in the "service co-design [11]".

\section{Conclusions and Further Research}

This research work introduced a study aimed at understanding how digital technologies influence services characteristics in service delivery processes. To do so, it proposes a novel classification of service provider - customer interactions supported by digital technologies with two dimensions: (a) the presence and the role of the service provider in a service delivery process, and (b) the presence and the role of the customer of the service in a service delivery itself. The achieved results underline that digital technologies modify both the characteristics and delivery processes of services. Moreover, the degree of influence of digital technologies can be amplified and/or mitigated by the level of involvement of a customer and/or a service provider in a service delivery process. In other words, the planning and managing of the processes, competencies, and resources involved in a service delivery depends on the different types of service provider - customer interactions (viz. $\mathrm{H} 2 \mathrm{H}, \mathrm{H} 2 \mathrm{M}$, and M2M).

We believe that this work can have interesting managerial implications as it helps service managers and practitioners understand how to design/manage service delivery processes for different types of service provider - customer interactions. However, this research work presents some limitations. First, it is based exclusively on a theoretical 
evaluation and a position that arises from the considerations of a group of researchers and practitioners*. Therefore, it would be necessary to deeply study the feasibility of the considerations that emerge when assessing whether services characteristics change in relation to the different types of service, customer, and industry. Moreover, empirical explorations should be carried out to analyse how different digital technologies impact on the different components of a service delivery process (viz. activities, resources, skills, infrastructure, measures) as well as to highlight their implications on the whole service lifecycle, from the interpretation of customer needs to the measurement of achieved results.

Further research should include the influence of digital technologies in service quality determinants, and in the structure of service delivery processes in reference to their service blueprinting elements (viz. customer actions, front-stage, back-stage, support processes, physical evidence, inventor, and line of visibility) [12].

\section{References}

1. Lightfoot, H.W., Baines, T., Smart, P.: Examining the Information and Communication Technologies Enabling Servitized Manufacture. Proc. Inst. Mech. Eng. Part B: J. Eng. Manuf. 225(10),1964-1968 (2011). doi: 10.1177/0954405411399019

2. Belvedere, V., Grando, A., Bielli. P.: A Quantitative Investigation of the Role of the Information and Communication Technologies in the Implementation of a Product-service System. Int. J. Prod. Res. 51(2), 410-426 (2013). doi: 10.1080/00207543.2011.648278

3. Zeithaml, V.A.: Service Excellence in Electronic Channels. Manag. Serv. Qual. 12(3), 135139 (2002). doi: 10.1108/09604520210429187

4. Parasuraman, A., Berry, L.L., Zeithaml, V.: Refinement and Reassessment of the SERVQUAL Scale. J. Retailing 67(4), 420-450 (1991).

5. Moeller, S.: Characteristics of Services - A New Approach Uncovers their Value. J. Serv. Mark. 24(5), 359-368 (2010). doi: 10.1108/08876041011060468

6. Ardolino, M., Rapaccini, M., Saccani, N., Gaiardelli, P., Crespi, G., Ruggeri, C.: The Role of Digital Technologies for the Service Transformation of Industrial Companies. Int. J. Prod. Res. 56(6), 2116-2132 (2018). doi: 10.1080/00207543.2017.1324224

7. Cook, D.P., Goh, C.-H., Chung, C.H.: Service typologies: a state of the art survey. Prod. Oper. Manag. 8(3), 318-338 (1999).

8. West, S., Gaiardelli, P., Rapaccini, M.: Exploring Technology-driven Service Innovation in Manufacturing Firms through the Lens of Service Dominant Logic. IFAC-PapersOnLine, 51(11), 1317-1322 (2018). doi: 10.1016/j.ifacol.2018.08.350

9. Campbell, C.S., Maglio, P.P., Davis, M.M.: From self-service to super-service: a resource mapping framework for co-creating value by shifting the boundary between provider and customer. Inf. Syst. E-Bus. Manag. 9(2), 173-191 (2011)

10. Storbacka, K.: Extending Service-Dominant Logic. In: Vargo, S., Lusch, R. (eds.) The SAGE Handbook of Service-Dominant Logic, pp. 635-638 SAGE Publishing, Thousand Oaks (2018)

11. Pezzotta, G., Cavalieri, S., Romero, D.: Collaborative Product-Service Systems Engineering: Towards an Active Role of Customers and Stakeholders in Value Co-Creation, 23th International Conference on Engineering, Technology and Innovation, ICE/ITMC 2017, pp. 1247-1254 (2017). doi: 10.1109/ICE.2017.8280023

12. Stickdorn, M., Schneider, J.: This is Service Design Thinking: Basics, Tools, Cases. John Wiley \& Sons Inc., Hoboken (2011)

\footnotetext{
* IFIP WG5.7 SIG on "Service Systems" - https://www.ifipwg57.org/special-interest-groups/
} 